\title{
Autosomal dominant hyperinsulinism due to SUR1 deficiency
}

INSERM

\section{Source}

INSERM. (1999). Orphanet: an online rare disease and orphan drug data base. Autosomal dominant hyperinsulinism due to SUR1 deficiency. ORPHA:276575

Autosomal dominant hyperinsulinism due to SUR1 deficiency is a form of diazoxidesensitive diffuse hyperinsulinism (DHI), characterized by hypoglycemic epiosodes that are usually mild, escaping detection during infancy and usually a good clinical response to diazoxide. Autosomal dominant hyperinsulinism due to SUR1 deficiency usually has a milder phenotype when compared to that resulting from recessive K-ATP mutations (recessive forms of Diazoxide-resistant hyperinsulinism, see this term). 